\title{
Mircea Eliade în perioada exilului parizian
}

\author{
Prof. univ. dr. Daniel GĂLĂȚANU \\ Universitatea „Dunărea de Jos” din Galați
}

\begin{abstract}
This article aims to clarify the main points in the Parisian exile of Mircea Eliade, taking account of the socio-political context loaded, "hard" of the fourth and fifth decades in Europe. Caught in the trap of political exile, but taking advantage of the abundance of libraries in the West, Eliade became the "refused one" of the Comintern and the Socialist International. Despite the obstacles of disturbance and the Soviets long right-hand, he manages to become spiritus rector of "fugitives" cultural elites in Paris, polarizing around his big personality the intelighentia of all Romanians in exile.
\end{abstract}

Keywords: Mircea Eliade, exile, Paris, journal.

Din Jurnalul său intim (și singurul său confident de încredere care 1-a însoțit pe toată perioada exilului) aflam că, în momentul sosirii sale la Paris, Mircea Eliade avea 38 de ani și, spre deosebire de ceilalți care erau obligați s-o ia complet de la-nceput, de la zero, el avea șansa de a avea aici rude, prieteni și colegi. De altfel, în privința Jurnalului, Eugen Simion spune că Mircea Eliade însuși este cel care ,,a introdus jurnalul intim, ca gen literar, în literatura română și, în genere, a mers in plina dominație a structuralismului (în studiile sale privind istoria religiilor) și, în etica, a noului roman împotriva curentului general. A continuat să scrie, în exil, în limba română și, cum arată scrisorile sale din această perioadă, urmărește cu atenție fenomenul cultural românesc." 2

Cum observam în ultima mea carte dedicată farurilor culturii române din exil ${ }^{3}$, Eliade ajunge să se integreze destul de repede în viața culturală a Oraşului Luminilor. De fapt, el nu se simte deloc străin aici. Ca de obicei, în momentele importante ale biografiei lui Eliade, totul se petrece sub o stea

\footnotetext{
2 Eugen Simion, Mircea Eliade - Nodurile și semnele prozei, Ed. Virtual, București, 2010, p. 3 (http://books.corect.com/ro/books/preview/450/pdf);

${ }^{3}$ Daniel Gălățanu Echos roumains dans la culture française au XXe siècle (2ème édition, revue, corrigée et augmentée), Ed. Zigotto, Galați, 2012;
} 
norocoasă. Mărturisește, de altfel, în Jurnalul ${ }^{4}$ său: „Foarte repede l-am întâlnit pe Ștefan Lupașcu, Georges Dumézil, René Grousset și am avut ocazia să cunosc câțiva indianiști importanți: Louis Rénou, Jean Filliozat, Paul Masson, Oursel. Recomandat de Rénou și Dumézil, am fost ales membru al Societății Asiatice". ${ }^{5}$

Eliade se întâlnește și cu alți români celebri deja stabiliți la Paris:

„Însoțit de Cioran, m-am dus să vizitez într-o după-amiază, pe Elena Văcărescu, care tocmai fusese numită consilier cultural pe lângă Ambasada României. L-am întâlnit, după cinci ani, pe Eugen Ionescu, am cinat în apartamentul lor, de pe strada Claude-Terrasse și Rodica mi-a arătat-o cu mândrie pe fiica lor, Marie-France Ionescu, care tocmai sărbătorise primul său an de viață. I-am întâlnit și pe foștii mei studenți, Mariana și Mihai Șora...Am cunoscut mulți români la Paris și m-am împrietenit repede cu ei." 6

Într-adevăr, la Paris, Eliade cunoaște un număr impresionant de români și se împrietenește foarte repede cu ei, căci nimeni nu avea, ca el, talentul și cultul prieteniei. În acest Paris al refugiului, al deznădejdii, al divergenței și al răzbunării, el este singurul capabil să înțeleagă și să adune la un loc persoane atât de diferite, de divergente, de balcanice și de eclectice.

Pe 8 octombrie 1846, el își inaugurează ciclul de conferințe pe lângă catedra de mitologie comparată a Sorbonnei. La acest eveniment participă Georges Dumézil, omniprezentul său protector, dar și tibetanista Marcelle Lalou. În februarie 1947, el publică în Revista Istoriilor religioase, primul său studiu apărut în Franța, Chestiunea Șamanismului .

Eliade muncește între 12 și 14 ore pe zi, dar este întrerupt uneori de „activitatea politică”. Ministerul Educației din Franța ar dori să-i ofere o catedră de titular la Școala de Înalte Studii, dar cere, în prealabil, avizul Ambasadei Române. Ambasada cere avizul șefilor politici din România (care, în acea vreme era sub ocupație sovietică) și răspunsul firesc este: niet $^{8}$.

\footnotetext{
${ }^{4}$ Până la restituirile lui Mircea Handoca, Jurnalele lui Eliade nu au fost publicate niciodată. Toate fragmentele din Jurnal sunt extrase din: Cornel Ungureanu, La vest de Eden,Ed. Amarcord, Timișoara, 1995;

${ }^{5}$ Apud Cornel Ungureanu, op. cit., p.71;

${ }^{6}$ Ibid.

${ }^{7}$ Cf. Ibid., p. 73;

${ }^{8}$ Cf. Mircea Handoca, Dosarul Eliade, NIET !, Humanitas, București, 1994, (p. 142-158), p. 147;
} 
De fapt, Mircea Eliade este foarte discret în jurnalul său și evită să enumere toate problemele pe care le-a avut în perioada dintre 1945 și 1948. Nu doar Ambasada și profesorul Stoilov primesc răspunsul niet la orice solicitare cu privire la Eliade, ci și toate instituțiile franceze care ar fi vrut să-1 angajeze sau să-l protejeze. În România, forțele de ocupație sovietice îi caută „pe criminalii de război” și pe „autorii dezastrului” României: fasciști, naziști, legionari. În zelul lor „revoluționar”, unii din prietenii lor îi „demască”. Iată dușmanul: este Eliade, este Cioran! ${ }^{9}$

Vechile polemici provocate de Moscova în cel de-al patrulea deceniu, sunt continuate acum de cei care au rămas să susțină puterea sovietică. Zaharia Stancu, Miron Radu Paraschivescu, Oscar Lemnaru, scriu articole incendiare despre „criminalii de război”. O bună parte din cei care-l înjuraseră pe Eliade în deceniul al patrulea s-au întors acum la București pe tancurile sovietice. Ei au numeroase contacte și numeroși aliați în țările occidentale. La Paris, Eliade va fi vânat nu doar de noile autorități ale statului român, ci și de Internaționala Socialistă, aureolată de postura de câștigătoare a războiului. ${ }^{10}$

Primele reviste din exil apar în momentul în care toată lumea își dă seama, în sfârșit, că războiul se terminase definitiv; este vorba de războiul prin care Uniunea Sovietică ocupase estul și sud-estul european. Un alt război era pe cale să înceapă, desigur, Războiul Rece.

Exilații se aflau deja în plin război și principala lor grijă era să salveze valorile spirituale ale națiunii noastre, pentru că însăși națiunea română era amenințată în fibra ei.

Revistele pe care le va coordona și în care Eliade va scrie, în perioada cuprinsă între 1949 și 1952, diverse articole, eseuri, analize și sinteze asupra fenomenului românesc, sunt numeroase: Indreptar, Uniunea Română, Caete de dor, Orizonturi. În paginile lor, el va lansa anchete și va încerca să definească momentul politic pe plan european și să explice extrema importanță a României în contextul cultural continental, devenind astfel, o dată în plus, conducătorul forțelor culturale care se strâng în jurul lui, căcă el este, de departe, singura personalitate a epocii sale, capabilă să construiască în jurul său un centru de rezistență și de autoritate incontestabile și de care, întreg exilul românesc avea nevoie ca de aer. ${ }^{11}$

\footnotetext{
${ }^{9}$ Cf. Ibid

${ }^{10} \mathrm{Ibid}$.

${ }^{11}$ Cornel Ungureanu, op. cit., p.74;
} 
Încrâncenarea sa anticomunistă dovedită încă din tinerețe îi aduce încrederea celor care simt nevoia să se apere, în țara lor sau în exil, de ofensiva stângii. Astfel, în mod paradoxal, acest scriitor care nu are nici o vocație de lider, se vede, o dată în plus, cum am mai arătat ${ }^{12}$, pus în fruntea unui curent întreg de opinie ce avea nevoie de o autoritate coordonatoare și unanim acceptată. Așa cum o făcuse cu câțiva ani în urmă în România, Mircea Eliade își asumă misiunea de lider datorită capacității sale extraordinare de a se devota, fie unui prieten, fie unui proiect sau unei idei generale.

În acest fel, el va deveni din nou jurnalistul de sacrificiu, scriitorul și istoricul, ba chiar și pedagogul care se străduia să răspundă la întrebările puse de toți confrații săi. Cei exilați erau obligați să se organizeze și să selecteze valorile necesare supraviețuirii, căci exilul înseamnă mai ales supraviețuire. Mircea Eliade rămâne același jurnalist care cunoaște arta de a utiliza superlativele și stăpânește tehnica hiperbolei, scriitura sa sprijinindu-se pe arta de a seduce.

În articolul Împotriva disperării, Mircea Handoca ${ }^{13}$ ne arată un număr impresionant de pagini care ar putea să ne edifice asupra eseului românesc în 1950:

„În ceea ce privește exilul românesc, trebuie să menționăm că numărul de intelectuali era foarte redus în raport cu cel al vecinilor noștri. Celor câtorva sute de mii de unguri plecați în exil nu corespund decât câteva mii de români. Primenirea spirituală va fi astfel mai dificilă pentru noi decât pentru vecinii noștri.

In al doilea rând, intelectualii români trăiau, aproape toți, în mizerie. Faptul că au supraviețuit până acum și că supraviețuiesc încă, nu e un mare merit în sine, pentru că oricum, in occident nimeni nu moare de foame. Dar întrebarea care contează este câți dintre ei au supraviețuit în calitate de intelectuali, adică, câți dintre ei și-au putut exercita în continuare vocația și profesia? Căci pentru România de mâine, important cu adevărat nu este ca ei să fi supraviețuit muncind într-o fermă sau într-o mină, ci ca ei să fi supraviețuit ca intelectuali, ca elite. Ar trebui să înțeleagă, înainte de a fi prea târziu, că destinul culturii române de mâine se găsește în mâinile unor foarte puțini intelectuali și studenți care supraviețuiesc în afara frontierelor României; că acest destin al culturii coincide cu destinul politic al României de mâine."14

${ }^{12}$ Daniel Gălățanu,op. cit. p. 37;

${ }^{13}$ Mircea Handoca, Dosarul Eliade, NIET !, Humanitas, Bucarest, 1994, (p. 142-158), p. 145;

${ }^{14}$ Ibid., p. 147 ; 
Cu siguranță, cominterniștii instalați la București simțeau pentru Eliade o ură fără margini, date fiind toate articolele sale asupra rusificării României, asupra terorii ocupației sovietice, asupra dezrădăcinării totale impuse de vecinul de la Răsărit. Toate acestea îl desemnau ca fiind unul din cei mai importanți inamici ai „noii Românii”. Toți acești activiști aveau și un motiv în plus de a-l urî: ideea lui Eliade, recurentă și îndelung susținută, conform căreia istoria României se face în România ${ }^{15}$.

Eliade a pierdut războiul cu presa pariziană, căci proprii lui colegi de generație și de exil l-au trădat. Marele metafore ale operei sale de după 1945, obsedantele sale simboluri, par a aparține unei persoane pentru care istoria rămâne o cauză pierdută.

El va scrie după tragedia bombei atomice de la Hiroshima: „Istoria s-a sfârșit; începe postistoria. Dar ce este postistoria? Ce este omul postistoric?” Toți acești termeni lipsiți de claritate, Eliade încearcă să-i explice în nuvelele sale ${ }^{16}$. Fiind un bun creator de ficțiune, va încerca să se protejeze de realitatea opresivă, transferând asupra personajelor sale, experiențele pe care ar fi vrut să le trăiască el însuși.

Mai mult decât în memoriile, jurnalele și amintirile sale, Eliade cel adevărat se manifestă în nuvelele și romanele sale, căci tocmai aici el a decis să explice posibilitățile și uriașul potențial ascuns în sufletul omului comun, al oricăruia dintre noi.

Ceea ce s-a petrecut în această tumultuoasă perioadă pariziană i-a marcat întreaga existență și pe parcursul întregii sale vieți rămase, el nu va face decât să încerce să-și vindece rănile create de exil.

Abandonându-se muncii creatoare, Eliade își va continua itinerariul prin lumea aceasta și prin cea descrisă de religiile atât de dragi lui. La Londra sau la Lisabona se va claustra în biblioteci devorând tratate întregi și făcând mii de fișe de lectură. Aici și-a elaborat lucrările capitale: Tratat de Istoria religiilor și Mitul eternei reîntoarceri. Totala împlinire academică o va găsi abia peste ocean, la Chicago, tot acolo unde-și va găsi și sfârșitul lumesc, departe de țara natală, dar într-o perpetuă încercare de eternă reîntoarcere.

${ }^{15} \mathrm{Ibid}$.

${ }^{16}$ Cf. Ibid. 


\section{Bibliografie:}

1. Gălățanu, Daniel, Echos roumains dans la culture française au XXe siècle (2ème édition, revue, corrigée et augmentée), Ed. Zigotto, Galați, 2012;

2. Handoca, Mircea, Dosarul Eliade, NIET !, Humanitas, București, 1994;

3. Simion, Eugen, Mircea Eliade - Nodurile și semnele prozei, Ed. Virtual, București, 2010;

4. Ungureanu, Cornel, La vest de Eden,Ed. Amarcord, Timișoara, 1995.

\section{Sitografie:}

1. http://books.corect.com/ro/books/preview/450/pdf;

2. www.culture.gouv.fr.;

3. http://www.univ-lehavre.fr/ulh services/Travaux-de-Daniel-Galatanu.html 